\begin{tabular}{|c|c|c|c|}
\hline Case Reports in & \multicolumn{2}{|c|}{ Case Rep Gastroenterol 2020;14:80-86 } & \multirow[b]{2}{*}{$\begin{array}{l}\text { Karger } \\
\text { Open'access }\end{array}$} \\
\hline Gastroenterology & $\begin{array}{l}\text { DOI: } 10.1159 / 000506182 \\
\text { Published online: February 20, } 2020\end{array}$ & $\begin{array}{l}\text { ( } 2020 \text { The Author(s) } \\
\text { Published by S. Karger AG, Basel } \\
\text { www.karger.com/crg }\end{array}$ & \\
\hline & $\begin{array}{l}\text { This article is licensed under the } \\
\text { International License (CC BY-NC) } \\
\text { Usage and distribution for commerci }\end{array}$ & $\begin{array}{l}\text { mons Attribution-NonCommercial } 4.0 \\
\text { rger.com/Services/OpenAccessLicense). } \\
\text { quires written permission. }\end{array}$ & \\
\hline
\end{tabular}

\title{
Endoscopic Retrograde Cholangiopancreatography Leading to Pharyngeal Perforation
}

\author{
Umair M. Nasir ${ }^{\mathrm{a}} \quad$ Ahmed Ahmed $^{\mathrm{a}} \quad$ Dayna Panchal $^{\mathrm{a}} \quad$ Catherine Choi $^{\mathrm{a}}$ \\ Brandon Rodgers $^{a} \quad$ Matthew Kutner ${ }^{b}$ Sushil Ahlawat ${ }^{b}$ \\ aDepartment of Internal Medicine, Rutgers New Jersey Medical School, Newark, NJ, USA; \\ ${ }^{b}$ Division of Gastroenterology, Department of Medicine, Rutgers New Jersey Medical \\ School, Newark, NJ, USA
}

\section{Keywords}

Endoscopic retrograde cholangiopancreatography · Necrotizing fasciitis · Pharyngeal · Hypopharynx · Laceration

\begin{abstract}
Endoscopic retrograde cholangiopancreatography (ERCP) had become the favored method to access the pancreaticobiliary system because it is a safer and less invasive method compared to surgery. However, as with any procedure, ERCP comes with its own risks and potential complications. We present a unique case of a patient who underwent ERCP and developed necrotizing infection of the neck and a submandibular abscess. The patient is a 66 -year-old female who presented to an outside hospital with complaint of right upper quadrant abdominal pain, workup of which revealed choledocholithiasis. ERCP was attempted; however, cannulation was unsuccessful. The patient was discharged home after the procedure, but within $48 \mathrm{~h}$ she presented to our institution complaining of left-sided neck pain, dysphagia, and drooling. CT of the neck revealed extensive gas and fluid collections at the left submandibular space. The patient was taken to the operating room for drainage of the left neck abscess. Drainage and irrigation of the abscess yielded Streptococcus mitis and Hemophilus parainfluenza. The rest of patient's hospital course was uncomplicated, and she was discharged with appropriate follow-up. In the case of our patient, ERCP was complicated by a perforation of the hypopharynx. Pharyngeal perforation can be subclassified into supraglottic and infraglottic. The most
\end{abstract}

\section{KARGER}

Umair M. Nasir, DO

Department of Medicine, Rutgers New Jersey Medical School

185 South Orange Avenue

Newark, NJ 07103 (USA)

E-Mail Umairjc@njms.rutgers.edu 
frequent cause of perforations is due to increased pressure in an intrinsically weak anatomical region of the pharynx. Such perforations are commonly due to the advancement of the endotracheal tube or transthoracic echo probe, but can also be due to advancement of an endoscope.

(c) 2020 The Author(s)

Published by S. Karger AG, Basel

\section{Introduction}

Since its inception in the 1960s, endoscopic retrograde cholangiopancreatography (ERCP) has provided a safer and less invasive method to access the pancreaticobiliary system as opposed to surgery. As such, ERCP has increasingly become the favored method of accessing the pancreaticobiliary system due to its effectiveness as a diagnostic and therapeutic tool in the evaluation and treatment of choledocholithiasis, biliary strictures, biliary leaks, choledochal cysts, sphincter of Oddi dysfunction, tissue sampling, and much more. However, ERCP remains the most challenging of all gastrointestinal endoscopic procedures. Although considered a safe procedure, it carries a 5-10\% incidence of post-procedure complications, most commonly pancreatitis, hemorrhage, bowel perforation, and cholangitis $[1,2]$. The complication rate is dependent on several factors, including patient selection, skill of the endoscopist, and the complexity of the case [3]. Complications such as perforation below the oropharynx are well described in the literature; however, perforation in the oropharynx is not well described. Here, we present a unique case of a patient who underwent ERCP and subsequently developed a necrotizing infection of the neck and a submandibular abscess.

\section{Case Presentation}

The patient is a 66-year-old female who presented to an outside hospital with complaint of right upper quadrant abdominal pain, workup of which revealed choledocholithiasis. ERCP was subsequently performed; however, cannulation of the sphincter of Oddi was unsuccessful. After the procedure, the patient complained of a sore throat which was thought to be due to mucosal irritation from intubation and endoscopy and the patient was discharged. Less than $48 \mathrm{~h}$ later, the patient presented to our institution with complaint of left-sided neck pain, dysphagia, and drooling. The patient denied any abdominal pain at presentation. Vitals revealed a temperature of $38.1^{\circ} \mathrm{C}$, pulse of 102 , and blood pressure $141 / 78$. Labs were remarkable for elevated white blood cell count of $16.9\left(\times 10^{3} / \mu \mathrm{L}\right)$ with neutrophilic predominance of $86.4 \%$; total bilirubin was slightly elevated at $1.6 \mathrm{mg} / \mathrm{dL}$. All other labs were within normal limits, including the remaining components of complete blood count, complete metabolic panel, lipase $(23 \mathrm{U} / \mathrm{L})$, and lactate $(1.5 \mathrm{mmol} / \mathrm{L})$. CT of the neck revealed extensive gas and fluid collections at the left submandibular space (Fig. 1), extending throughout the parapharyngeal and submandibular spaces, and into the superficial soft tissues and carotid sheath with narrowing of the subglottic airway (Fig. 2). The patient was intubated for airway protection, started on broad-spectrum antibiotics with vancomycin, piperacillin-tazobactam plus clindamycin, and admitted to the intensive care unit. Within $12 \mathrm{~h}$ of arrival she was taken to the operating room for transcervical drainage of a deep left neck abscess. During the procedure, a $1.5-\mathrm{cm}$ tear in the glossotonsillar sulcus with purulent drainage was identified. The laceration communicated directly with the submandibular abscess. Drainage and irrigation of the abscess was performed and the tear was surgically repaired. Wound cultures yielded Hemophilus parainfluenza, which is known to inhabit the oral cavity, and in addition alpha 
hemolytic streptococci (Streptococcus mitis), a rare Stomatococcus species known to inhabit the upper gastrointestinal tract, was also identified. The patient was extubated after the procedure, and was continued on vancomycin and piperacillin-tazobactam. Results of blood cultures, taken upon admission, showed no growth, while white blood count tracked downward. At this point the patient was transferred out of the intensive care unit and started on oral antibiotics. The remainder of the patient's hospital course was uncomplicated, and she was discharged with a 10-day regimen of amoxicillin-clavulanate. Follow-up was scheduled with infectious disease, otolaryngology, and gastroenterology.

\section{Discussion}

ERCP is inherently one of the most challenging gastrointestinal endoscopic procedures. At least 180 procedures are required during training to gain a level of competence [4]. Furthermore, an adequate number of procedures is required to maintain proficiency and avoid complications as several large studies have shown increased hospital ERCP volume $(>200$ ERCP/year) correlates with better outcomes [5]. Additionally, older age, comorbid diseases, small bile duct diameter, and emergency procedures are all independent factors associated with complications [6]. Some common complications of ERCP include cholangitis, hemorrhage, and pancreatitis [2]. Uncommon complications such as perforation are reported in $<1 \%$ of cases and are seen mainly in patients with therapeutic intervention [7]. However, when they do occur, perforations are associated with high morbidity and mortality [8]. Perforations are most commonly reported in the esophagus, stomach, duodenum, periampullary region, and bile ducts [8]. Periampullary and bile duct perforations can be easily detected via extravasation of contrast from the biliary tree and are commonly treated conservatively with parenteral antibiotics; however, stenting can also be considered. Treatment of esophagus, stomach, or duodenum perforation requires immediate and aggressive antibiotic therapy along with surgical evaluation [9].

In the case of our patient, ERCP was complicated by an unrecognized pharyngeal perforation, specifically of the hypopharynx, which eventually led to necrotizing infection and abscess. The most frequent cause of pharyngeal perforation is iatrogenic due to mechanical instrumentation [10].

Although reported very little in the gastroenterology literature, pharyngeal and esophageal laceration have been previously described extensively in the cardiology literature in regard to transesophageal echocardiogram. Esophageal perforation during transesophageal echocardiogram most commonly occurs in the abdominal and intrathoracic portion of the esophagus and less commonly in the pharyngeal regions of the esophagus [10]. Perforation can be due to inadequate skills, unexpected anatomical or mucosal damage, secondary pressure-induced ischemia, or heat by the probe $[10,11]$. In cases in which there is a tenuous blood supply or a thin esophageal wall without a serosa, mean morbidity from perforation is higher as the esophagus cannot prevent dissemination of infection and inflammation $[12,13]$.

The hypopharynx and upper esophagus are most vulnerable to perforation because the esophageal wall has an intrinsic weakness caused by fibers crossing from the pharyngeal constrictor and the cricopharyngeal muscles. Neck extension, in a patient with anterior vertebral osteophytes, can increase the risk of perforation at the hypopharynx and upper esophagus thought to be due to stretching of the mucosal and muscular fibers $[2,5]$. Shearing stress, prolonged flexion of the probe, and probe mobilization in a locked position may result in esophageal tearing or perforation [12]. 
Pharyngeal perforation can be subclassified into supraglottic and infraglottic. Infraglottic perforations are more commonly associated with advancement of an endotracheal tube during intubation since most intubations are carried out under direct visualization [11]. Advancement of an endoscope in an already intubated patient can lead to a supraglottic perforation $[10,14]$. In the case of our patient, the hypopharynx tear, which is supraglottic in nature, was most likely due to ERCP scope advancement in an intubated patient.

Patients with perforation in the supraglottic or infraglottic pharynx can present with similar clinical symptoms of dysphagia, fevers, oral bleeding, and subcutaneous emphysema of the neck $[14,15]$. Several strategies can be used to localize the source of the tear. An infraglottic lesion is likely present if blood is seen in the endotracheal tube, the end-tidal $\mathrm{CO}_{2}$ is decreased, or tidal volume is decreased $[10,16]$. Supraglottic lesions are more likely if bleeding is observed outside of the endotracheal tube. If there is early-onset subcutaneous emphysema or pneumothorax, pneumomediastinum can be observed due to an infraglottic lesion secondary to endotracheal tube advancement [16]. In our case, no blood was observed in the endotracheal tube and subcutaneous emphysema did not develop until $24 \mathrm{~h}$ after the procedure. Therefore, we conclude that the pharyngeal perforation observed in our patient was a supraglottic lesion.

When perforations do occur, they result in infection with anaerobic and aerobic microbes which inhabit the oropharynx via local translocation. Commonly seen organisms in such cases include H. parainfluenza, which is known to inhabit the oral cavity $[17,18]$, and alpha hemolytic streptococci (S. mitis), known to inhabit the upper gastrointestinal tract [19].

There should be a high index of suspicion of perforation in any patient who presents with cervical tenderness after mechanical manipulation of the esophagus. Early diagnosis can improve morbidity and decrease mortality [15]. Along with surgical consultation, treatment should include broad-coverage antibiotics selection based on the severity and presentation.

In conclusion, perforations and abscess formation after ERCP have been reported in $<1 \%$ of cases. When they do occur, they most commonly occur below the oropharynx and are colonized by gastrointestinal and respiratory tract flora [17-19]. Because of the intrinsic weakness in the pharyngeal musculature, shearing stress from advancement of an endoscope can lead to perforation. As such, extreme care should be taken when advancing the scope in the oral cavity. If oral pharyngeal perforation is suspected, it should be quickly identified and appropriately treated.

\section{Acknowledgments}

The authors would like to thank the staff at the Department of Medicine and the Department of Gastroenterology at Rutgers New Jersey Medical School for their assistance in the development of the drafts and final manuscript.

\section{Statement of Ethics}

The subject in this case report has given her informed consent to publish her case, including the publication of images. This report did not need IRB approval based on the Department of Health and Human Services criteria. 
Nasir et al.: ERCP Leading to Pharyngeal Perforation

\section{Disclosure Statement}

The authors have no conflicts of interest to declare.

\section{Funding Sources}

The authors confirm that they have no funding sources to disclose.

\section{Author Contributions}

Umair M. Nasir contributed to the conception, literature review, and drafting and revision of the article. Dayna Panchal and Catherine Choi contributed to the revision of the article. Ahmed Ahmed and Brandon Rodgers contributed to the literature review. Matthew Kutner and Sushil Ahlawat contributed figures, figure explanations, and drafting and revision of the article.

\section{References}

1 Prachayakul V, Aswakul P. Endoscopic retrograde cholangiopancreatography-related perforation: management and prevention. World J Clin Cases. 2014 Oct;2(10):522-7.

2 Baillie J. Complications of endoscopy. Endoscopy. 1994 Jan;26(1):185-203.

3 Chen M, Wang L, Wang Y, Wei W, Yao YL, Ling TS, et al. Risk factor analysis of post-ERCP cholangitis: A single-center experience. Hepatobiliary Pancreat Dis Int. 2018 Feb;17(1):55-8.

4 Jowell PS, Baillie J, Branch MS, Affronti J, Browning CL, Bute BP. Quantitative assessment of procedural competence. A prospective study of training in endoscopic retrograde cholangiopancreatography. Ann Intern Med. 1996 Dec;125(12):983-9.

5 Varadarajulu S, Kilgore ML, Wilcox CM, Eloubeidi MA. Relationship among hospital ERCP volume, length of stay, and technical outcomes. Gastrointest Endosc. 2006 Sep;64(3):338-47.

6 Talukdar R. Complications of ERCP. Best Pract Res Clin Gastroenterol. 2016 Oct;30(5):793-805.

7 Andriulli A, Loperfido S, Napolitano G, Niro G, Valvano MR, Spirito F, et al. Incidence rates of post-ERCP complications: a systematic survey of prospective studies. Am J Gastroenterol. 2007 Aug;102(8):1781-8.

8 Chandrasekhara V, Khashab MA, Muthusamy VR, Acosta RD, Agrawal D, Bruining DH, et al.; ASGE Standards of Practice Committee. Adverse events associated with ERCP. Gastrointest Endosc. 2017 Jan;85(1):32-47.

9 Enns R, Eloubeidi MA, Mergener K, Jowell PS, Branch MS, Pappas TM, et al. ERCP-related perforations: risk factors and management. Endoscopy. 2002 Apr;34(4):293-8.

10 Côté G, Denault A. Transesophageal echocardiography-related complications. Can J Anaesth. 2008 Sep;55(9):622-47.

11 Sainathan S, Andaz S. A systematic review of transesophageal echocardiography-induced esophageal perforation. Echocardiography. 2013 Sep;30(8):977-83.

12 Pasricha PJ, Fleischer DE, Kalloo AN. Endoscopic perforations of the upper digestive tract: a review of their pathogenesis, prevention, and management. Gastroenterology. 1994 Mar;106(3):787-802.

13 Saphir JR, Cooper JA, Kerbavez RJ, Larson SF, Schiller NB. Upper airway obstruction after transesophageal echocardiography. J Am Soc Echocardiogr. 1997 Nov-Dec;10(9):977-8.

14 Agha-Mir-Salim P, Beck R, Bloching M, Berghaus A. [Endoscopic treatment of iatrogenic esophageal perforation]. Laryngorhinootologie. 2000 Jan;79(1):39-42. German.

15 Fernandez FF, Richter A, Freudenberg S, Wendl K, Manegold BC. Treatment of endoscopic esophageal perforation. Surg Endosc. 1999 Oct;13(10):962-6.

16 Myers EM. Hypopharyngeal perforation: a complication of endotracheal intubation. Laryngoscope. 1982 May;92(5):583-5.

17 Bansal R, Barakat M, Chun S, Rosberger S, Baum J, Tiba M. A case of unresolved and worsening retroperitoneal abscess. Case Rep Gastrointest Med. 2018 Jan;2018:6740734. 
Nasir et al.: ERCP Leading to Pharyngeal Perforation

18 Patel SB, Hashmi ZA, Marx RJ. A retroperitoneal abscess caused by Haemophilus parainfluenza after endoscopic retrograde cholangiopancreatography and open cholecystectomy with a common bile duct exploration: a case report. J Med Case Rep. 2010 Jun 3;4:170.

19 Riahi S, Hansen J, Bjerre J, Kragsbjerg P. ERCP complicated by a retroperitoneal abscess caused by Haemophilus influenzae and Haemophilus parainfluenzae. Gastrointest Endosc. 1998 May;47(5):417-8.

This case was presented as a poster presentation, in October 2019, at the American Collage of Gastroenterology National Conference in San Antonio, Texas

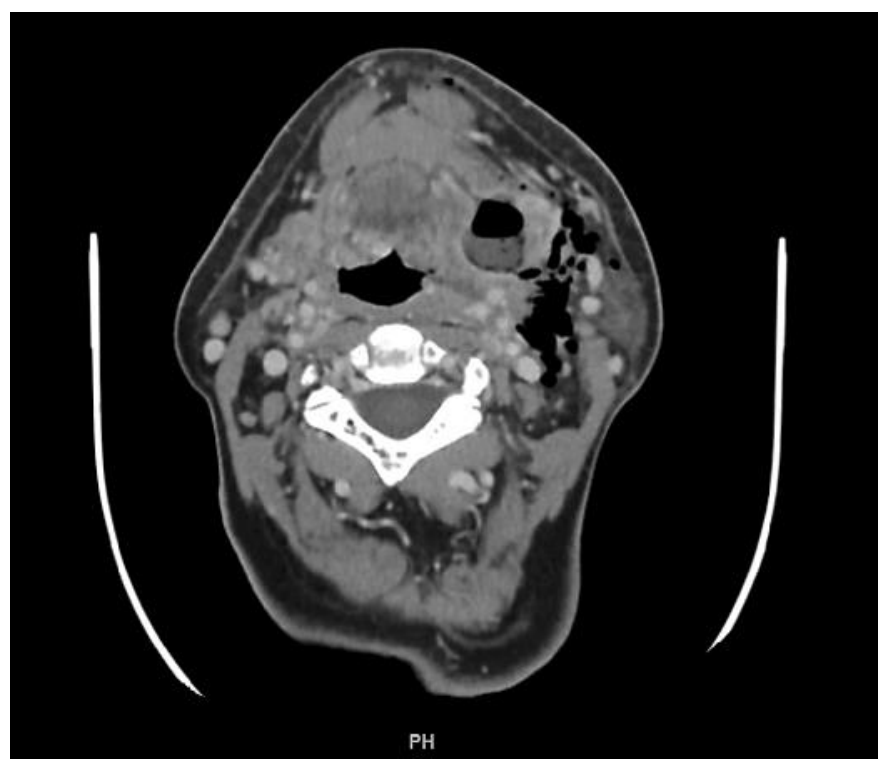

Fig. 1. Axial view of a CT with contrast of neck showing peripherally enhancing fluid collection at the left submandibular space along with extensive gas collection extending from the left submandibular to the left parapharyngeal space. 


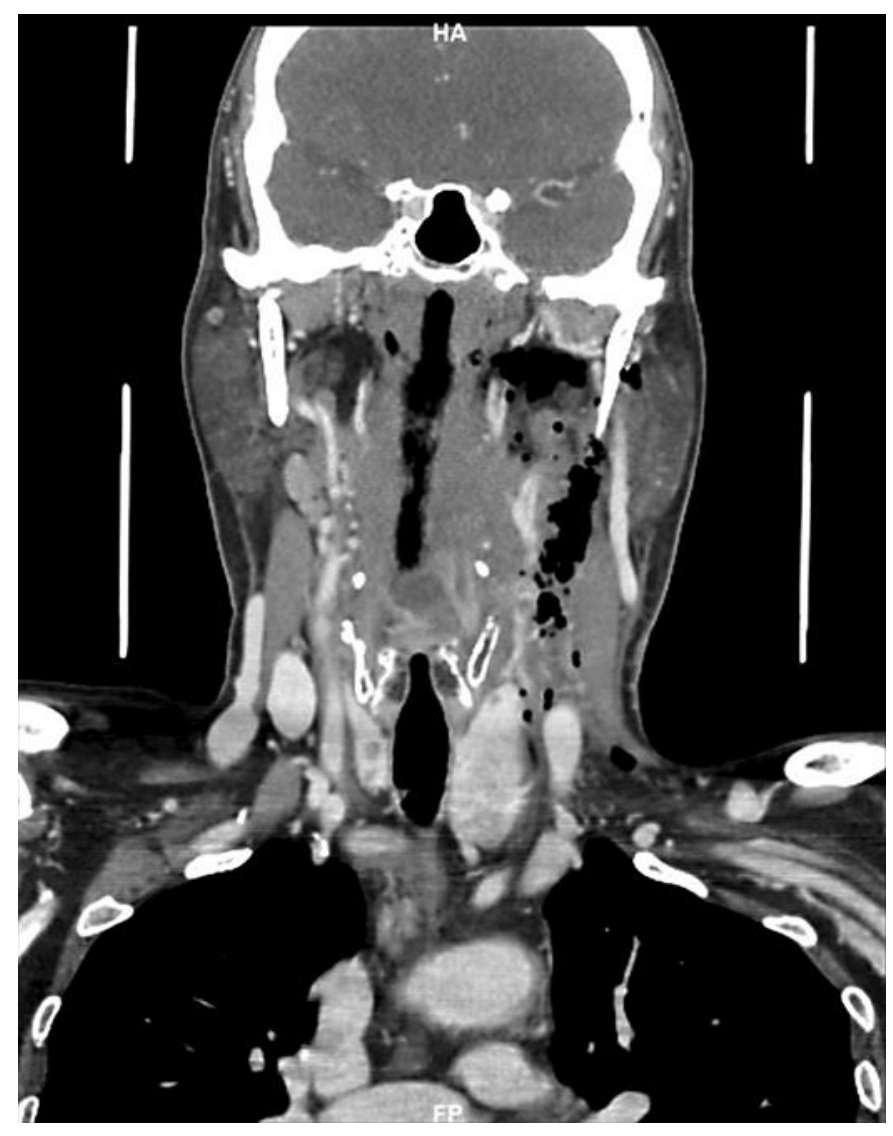

Fig. 2. Coronal view of a CT with contrast of neck revealing gas extending from the left parapharyngeal region into the submental, submandibular space and the carotid sheath. The left submandibular gland is enlarged, avidly enhancing, and deviated inferiority. 